\title{
Cariology Education in Canadian Dental Schools: Where Are We? Where Do We Need to Go?
}

\begin{abstract}
Svetlana Tikhonova, DDS, PhD; Félix Girard, DDS; Margherita Fontana, DDS, PhD
Abstract: The aim of this study was to document cariology education across Canadian dental schools. Ten faculty members who supervise cariology education at each of the ten Canadian dental schools were invited to participate in the study in 2016. An adapted version of the European Organization for Caries Research-Association for Dental Education in Europe cariology curriculum group questionnaire was used. Representatives of all ten dental schools completed the questionnaire, for a $100 \%$ response rate. In four schools, cariology and restorative dentistry were taught by the same department. Five schools had didactic/ laboratory courses focusing primarily on cariology as well as a specific written curriculum. Six schools provided cariologyrelated hands-on workshops/laboratories before students started working with patients. In teaching cariology, seven institutions included dental hard tissues defects. The following caries detection methods were addressed didactically in cariology education: visual (10/10 total schools), tactile (9/10), International Caries Detection and Assessment System criteria (6/10), caries activity assessment (9/10), radiographic (10/10), and other detection tools (8/10). Seven schools charted activity of carious lesions in clinic. Only one school used the concept of caries risk assessment regularly in clinic. Clinical cariology teaching was carried out mostly by private dentists hired as clinical instructors (7/10) and faculty members involved in didactic cariology education (9/10). Calibration of faculty members for caries detection criteria was reported by only one school. The main concern reported by all institutions was the difficulty of implementing didactic instruction on cariology into clinical training. This study found that contemporary cariology concepts are in the process of being implemented in didactic education across Canadian dental schools, but all schools lacked appropriate integration of cariology education into clinical training. These findings suggest a need for harmonization of evidence-based cariology education in Canada.
\end{abstract}

Dr. Tikhonova is Faculty Lecturer, Faculty of Dentistry, McGill University; Dr. Girard is Assistant Professor, Department of Oral Health, Faculty of Dentistry, Université de Montréal; Dr. Fontana is Professor of Cariology, School of Dentistry, University of Michigan. Direct correspondence to Dr. Svetlana Tikhonova, Faculty of Dentistry, McGill University, 2001 McGill College Ave., Montreal H3A1G1, Canada; svetlana.tikhonova@mcgill.ca.

Keywords: dental education, dental schools, dental caries, cariology, caries management, curriculum, Canada

Submitted for publication 6/30/17; accepted 9/7/17

doi: $10.21815 / J D E .018 .006$

$\mathrm{T}$ The evidence supporting a non-surgical treatment approach for carious lesions and the need to manage the dental caries disease process in a risk-based manner is growing. ${ }^{1}$ The final goal of this approach is to maintain the healthy natural dentition in populations for life. ${ }^{2}$ Nevertheless, there continues to be a large gap between evidence-based caries management guidelines and what is done in clinical practice. ${ }^{1,3}$ Many dentists continue to focus on the drill-related approach for caries treatment, resisting the adoption of more conservative approaches for preservation of tooth structure and pulpal health. ${ }^{1,2,4} \mathrm{~A}$ study conducted in the 1990s in Montreal among sixto-nine-year-old schoolchildren found that, within three to six months after the baseline examination, $73-86 \%$ of new restorations in first permanent molars were placed by general practitioners in sound or noncavitated tooth surfaces. ${ }^{5} \mathrm{~A}$ recent systematic review, based on 17 studies conducted in various countries, reported that dentists worldwide overused operative approaches for both non-cavitated and cavitated carious lesions. ${ }^{6}$ Those investigators also reported that diagnostic thresholds for operative treatment of carious lesions had undergone few changes from 15 or 30 years ago. A survey of California dentists found that up to $43 \%$ of respondents would restore proximal lesions reaching the enamel-dentinal junction or occlusal lesions within the enamel. ${ }^{7}$ Thus, the operative-based approach to managing dental caries still prevails among dental practitioners, with teeth entering the re-restorative cycle maybe unnecessarily or too early. ${ }^{4}$

The reasons for dentists' resistance to adopt a contemporary caries paradigm are multiple and can be related to dental education, inconsistancies in clinical guidelines, policies, remuneration systems, and political and psychological factors. ${ }^{1,3}$ Elderton emphasizes, "It is well known that most 'treatment' 
undertaken in dental practice is not at variance with what was taught in dental school. But the dental school was yesterday. Today's patients require today's care!"4

Cariology education in predoctoral dental education plays an essential role in establishing the foundation of future dentists' caries management practices since their caries management "scripts" begin to develop in dental school. ${ }^{8}$ Researchers have emphasized that cariology education in dental schools should reflect contemporary caries management paradigms and there is a continuous need for its reappraisal over time. ${ }^{3,9}$ Despite this, numerous dental schools still continue preparing dentists mostly to become proficient in curative and rehabilitative approaches to oral diseases. ${ }^{10}$

In 2010, a European Core Curriculum for Cariology (ECCC) for undergraduate dental students was developed by the curriculum committee of the European Organization for Caries Research (ORCA) and the Association for Dental Education in Europe (ADEE). ${ }^{11}$ The main purpose of the curriculum is to define essential evidence-based competencies related to cariology teaching for dental students that all schools should consider. ${ }^{12}$ A consensus-building workshop to adapt the ECCC to the needs of U.S. dental education was held in Boston in 2015, and the resulting Core Curriculum Framework in Cariology for U.S. Dental Schools was recently published. ${ }^{13}$ There are five domains in the curriculum: knowledge base; risk assessment, diagnosis, and synthesis; treatment decision making: non-surgical management; surgical therapy; and evidence-based cariology in clinical and public health practice. Each domain contains objectives and learning outcomes. To our knowledge, there is no core cariology curriculum framework for Canadian dental schools. At the same time, the education framework for development of competence in dental programs proposed by the Association of Canadian Faculties of Dentistry (ACFD) is not specific for cariology teaching and does not explicitly address all important domains associated with the subject of cariology. ${ }^{14}$ Thus, there is a need for a core cariology curriculum for Canadian dental schools. This curriculum will help standardize and guide an approach for teaching cariology in Canada and will facilitate implementation of the nonoperative caries management paradigm into clinical practice. The first step to facilitate the development of a core cariology curriculum in Canada is to assess the current state of cariology education. Therefore, the aim of this study was to document cariology education across Canadian dental schools.

\section{Materials and Methods}

The study protocol was approved by the Institutional Review Board of the University of Montreal (15-140-CERES-D). A descriptive survey design was used to investigate predoctoral cariology teaching in Canadian dental schools. The population was the faculty members in charge of predoctoral cariology education in each dental school: University of Alberta, McGill University, Université Laval, University of British Columbia, University of Manitoba, University of Western Ontario, Dalhousie University, University of Saskatchewan, University of Toronto, and Université de Montréal. Data concerning cariology teaching was collected from a representative of each dental school by means of an online semistructured questionnaire using the Research Electronic Data Capture software (REDCap). Email messages including a brief explanation of the project's objectives, an informed consent form, and the link to the questionnaire were sent to the deans or associate deans of the ten schools. The deans were asked to forward the email to the key person(s) responsible for cariology education at the faculty. In some cases, persons responsible for cariology teaching were contacted directly. The schools who agreed to participate in the project were asked to complete the questionnaire within one month. After one month, a reminder was sent to the dental schools.

The questionnaire used was adapted by the Section on Cariology of the American Dental Education Association (ADEA) from the questionnaire developed by the cariology curriculum committee of ORCA and ADEE. ${ }^{15,16}$ In total, the questionnaire consisted of 34 closed and open-ended questions associated with fields of education in cariology, divided into three major sections. At the start of the questionnaire, a definition of cariology was provided. The first set of questions sought information about the academic institution and the respondent's involvement in cariology teaching. The second series of questions focused on the cariology education structure. These questions included a review of cariology-related competencies, presence of preclinical workshops/ laboratories, inclusion of other defects of dental hard tissues (e.g., erosion, abrasion), and the primary textbook used for cariology teaching. The third set of questions related to the specific content of cariology education: nomenclature and classification system used, epidemiology, histopathology, etiology, role of saliva, diet, microbiology, caries diagnosis and risk assessment, non-operative and operative strategies of caries management, and details about implementation 
in didactic and clinical settings. Descriptive statistics focused on frequency distribution of categorical variables were used to analyze and report the data in the REDCap software.

\section{Results}

The online questionnaires were completed by representatives of all ten Canadian dental schools, making the response rate $100 \%$. Among the respondents, four reported that cariology teaching was their primary responsibility, five were one of several faculty members involved in cariology teaching, and one was not directly involved in cariology teaching but was assigned by the university to complete the survey.

In four dental schools, cariology and restorative dentistry were taught by the same department. Among departments/divisions primarily responsible for teaching cariology were the following: Basic Sciences, Restorative/Operative Dentistry, Radiology, Oral Health Sciences, Oral Biology, Dental Clinical Sciences, and Oral Health.

The usual training to become a dentist takes four to five years. In eight dental schools, didactic/ laboratory education in cariology was for students in the first and second years. Four schools provided cariology education also in the third year and two schools in the fourth year.

In describing the primary cariology-related competencies, six respondents listed learning objectives and outcomes such as caries risk assessment, carious lesion severity assessment, surgical and nonsurgical management of caries, and other hard tooth defects. Two dental schools reported using competencies from the ACFD framework, and two schools reported using competencies from the National Dental Examining Board of Canada (NDEB). ${ }^{14,17}$

Among the primary recommended textbooks for teaching cariology, six schools used Dental Caries: The Disease and Its Clinical Management, ${ }^{18}$ and three schools used Fundamentals of Operative Dentistry: A Contemporary Approach. ${ }^{19}$ Among other recommended textbooks were Essentials of Dental Caries, ${ }^{20}$ Saliva and Oral Health, ${ }^{21}$ Primary Preventive Dentistry, ${ }^{22}$ Comprehensive Preventive Dentistry, ${ }^{23}$ The Prevention of Oral Disease, ${ }^{24}$ Paediatric Cariology, ${ }^{25}$ and Art and Science of Operative Dentistry, ${ }^{26}$ as well as various published articles/ documents.

Five respondents reported that their institutions had a specific written curriculum for cariology. Five schools had didactic/laboratory courses focusing primarily on cariology. Eight institutions had a discrete series of lectures or course modules on cariology that were part of a course or courses not focused primarily on cariology. The names of these courses were various: Restorative/Operative Dentistry, Preventive Dentistry, Dentistry Apprenticeship, Foundations of Dentistry, Transition to Clinic, Clinical Practice Junior and Senior Clerkship, Fundamentals of Medical Science, Introduction to General Practice, Core Biology, Core Pathology, Biological Basis of Oral Health and Disease, Microbiology, and Oral Radiology.

The vast majority of representatives said their schools ( $\mathrm{N}=8$ to 10$)$ addressed the following cariesrelated topics in their curricula: nomenclature in cariology; epidemiology of caries; diet, microbiology, saliva, and psychosocial determinants of caries; histopathology of caries; clinical and histological appearance of carious lesions; caries detection; caries risk assessment; and evidence-based dentistry in caries management (Table 1). Among the topics less frequently covered in cariology education were genetics and caries, epidemiology and physio-chemistry of dental erosion, and Atraumatic Restorative Technique. The following didactic non-surgical caries management strategies were addressed by most dental schools: professional and individual mechanical plaque removal, cariogenic diet modification, fluorides, dental sealants, antibacterial strategies, and xylitol-based strategies (Table 2). Less frequently addressed non-surgical caries management topics were $\mathrm{pH}$ neutralization strategies, management of salivary hypofunction, calcium-based strategies, and assessment of readiness for behavioral change. Seven dental schools included in their cariology teaching defects of dental hard tissues other than carious defects and dental erosion (e.g., abrasion, attrition).

Six dental schools provided cariology-related hands-on workshops/laboratories before students started working with patients. These activities focused on various topics: carious lesion detection and diagnosis, placement of dental sealants, application of fluoride varnish, oral self-care, caries risk assessment, and caries removal exercises for restorations. Among caries detection methods, schools addressed the following: visual detection, tactile detection, visual detection with magnification, caries activity assessment, radiographic detection of carious lesions, non-radiographic technology-assisted detection (e.g., fluorescence-based methods), International Caries Detection and Assessment System (ICDAS) 
terminology and criteria, and other caries diagnostic criteria such as the American Dental Association (ADA) Caries Classification System (Table 3).

The concept of caries risk assessment (CRA) was reported as being addressed by all ten dental schools in their didactic curricula. CRA tools varied by institution and included existing CRA instruments and in-house risk assessment tools (Table 4). Among factors assessed by in-house CRA tools were medical conditions, socioeconomic status, history of dental caries, oral hygiene, bacterial counts, diet, fluoride exposure, salivary function, carious lesions activity, tooth eruption status, root exposure, presence of fixed or removable appliances, gingival inflammation, and special needs.

Table 1. Topics addressed in cariology education in Canadian dental schools $(\mathrm{N}=10)$

\begin{tabular}{|c|c|}
\hline Topic & $\begin{array}{l}\text { Vumber of } \\
\text { Schools }\end{array}$ \\
\hline Nomenclature in cariology & 10 \\
\hline Epidemiology of dental caries & 9 \\
\hline Diet & 10 \\
\hline Microbiology & 10 \\
\hline Saliva & 10 \\
\hline Genetics & 4 \\
\hline Psychosocial and broader determinants & 8 \\
\hline Epidemiology of dental erosion & 5 \\
\hline Etiology of dental erosion & 10 \\
\hline Histopathology of dental caries & 8 \\
\hline Physico-chemistry of dental erosion & 6 \\
\hline $\begin{array}{l}\text { Clinical and histological appearance } \\
\text { of carious lesions }\end{array}$ & 10 \\
\hline Caries detection & 10 \\
\hline Detection of dental erosion & 10 \\
\hline Caries risk assessment & 10 \\
\hline $\begin{array}{l}\text { Removal of dental hard tissues affected by caries } \\
\text { (general discussion of threshold for removal } \\
\text { and how much to remove) }\end{array}$ & 10 \\
\hline Partial caries removal strategies & 8 \\
\hline $\begin{array}{l}\text { Considerations for caries associated with } \\
\text { restoration (secondary or recurrent caries) }\end{array}$ & 8 \\
\hline Considerations for root caries & 10 \\
\hline Atraumatic Restorative Technique & 6 \\
\hline Management of dental erosion & 10 \\
\hline Caries management in populations & 8 \\
\hline $\begin{array}{l}\text { Use of evidence-based dentistry in } \\
\text { caries management }\end{array}$ & 9 \\
\hline
\end{tabular}

Table 2. Non-surgical caries management strategies addressed in Canadian dental schools' didactic education in cariology $(\mathrm{N}=10)$

\begin{tabular}{lc} 
Caries Management Strategy & $\begin{array}{c}\text { Number of } \\
\text { Schools }\end{array}$ \\
\hline $\begin{array}{l}\text { Professional and individual mechanical } \\
\text { plaque removal }\end{array}$ & 10 \\
Cariogenic diet modification & 10 \\
Fluoride & 10 \\
Dental sealants & 10 \\
Antibacterial strategies & 9 \\
Xylitol-based strategies & 8 \\
Management of salivary gland hypofunction & 7 \\
Calcium-based strategies & 5 \\
pH neutralization strategies & 4 \\
Patient compliance with preventive programs & 10 \\
Assessment of readiness for behavioral change & 4 \\
Choice of appropriate preventive strategies & 10
\end{tabular}

Table 3. Caries detection methods taught in Canadian dental schools $(\mathrm{N}=10)$

\begin{tabular}{lc} 
Caries Detection Method/Criterion & $\begin{array}{c}\text { Number of } \\
\text { Schools }\end{array}$ \\
\hline Visual detection & 10 \\
Tactile detection & 9 \\
Visual detection with magnification & 6 \\
Radiographic detection of carious lesions & 10 \\
$\begin{array}{l}\text { Non-radiographic technology-assisted detection } \\
\text { (e.g., fluorescence-based methods) }\end{array}$ & 8 \\
$\begin{array}{l}\text { International Caries Detection and Assessment } \\
\text { System terminology and criteria }\end{array}$ & 6 \\
Caries activity assessment & 9 \\
\hline \hline
\end{tabular}

Table 4. Caries risk assessment tools used in Canadian dental schools $(\mathrm{N}=\mathbf{1 0})$

\begin{tabular}{ll} 
Tool & $\begin{array}{c}\text { Number of } \\
\text { Schools }\end{array}$ \\
\hline Caries Management by Risk Assessment (CAMBRA) & 4 \\
In-house caries risk assessment forms & 4 \\
Presence of active carious lesions & 2 \\
American Dental Association guidelines & 1 \\
American Academy of Pediatric Dentistry guidelines & 1
\end{tabular}


The choice of operative treatment decisions was reported by respondents in the following cases: white/brown spot lesions without cavitation (1/9 total schools), non-cavitated lesions with an underlying shadow (3/9), microcavities/enamel breakdowns (with no dentin exposed) (4/9), cavities with dentin exposure (8/9), and other (4/9). Among the other responses were the following: interproximal lesion with underlying shadow in a high caries risk patient; high caries risk patients when monitoring of lesions is not feasible; or the criteria varied depending on the clinical instructor. Eight respondents reported radiographic findings that indicate operative intervention depended on extent of the lesion and caries risk. There was a consensus among all respondents that carious lesions appearing in enamel and outer third of dentin on radiographs were not an indication for operative treatment.

Regarding the teaching of cariology in the clinics, full-time faculty members were the instructors in nine dental schools, along with private dentists hired as clinical instructors in seven schools. Only in one dental school were faculty members calibrated on caries diagnostic criteria. The following classification terminologies were being used in the schools' clinics: primary caries $(6 / 10)$, secondary caries $(7 / 10)$, cavitated lesion (6/10), microcavitated lesion (4/10), noncavitated lesion $(8 / 10)$, root caries $(8 / 10)$, active lesion (7/10), arrested lesion (7/10), and "watch" $(4 / 10)$. Only one school used caries risk assessment regularly in clinical training. For fourth-year students, four dental schools implemented the concept of Caries Management by Risk Assessment in clinical practice on a regular basis.

Representatives of five dental schools reported that cariology concepts taught didactically were only partly implemented in their institutions' clinical curricula. Four respondents reported that the cariology concepts were not implemented at all in clinical practice in their schools. At the same time, many respondents believed that their school's curriculum was evolving towards a more evidence-based approach on the management of caries. However, there was still a lack of integration between didactic and clinical teaching of caries. The calibration and coaching of part-time clinical instructors were complex challenges that needed to be better addressed, as well as insufficient emphasis on non-surgical management of caries and prevention in clinical teaching. Illustrative comments by respondents related to the clinical implementation of the caries management paradigm are
Table 5. Illustrative examples of comments related to caries management paradigm implementation

\section{Comments}

"A lot of improvements have been brought into the curriculum in the past years, but a lot still has to be done in order to minimize overtreatment and reach a good level of calibration between instructors/professors and students (the biggest challenge)."

"There is a disconnect between the didactic [information] taught in second year and what is taught in the clinic. I am not confident that the evidence shared in the cariology course is followed or considered in the clinic as the students are influenced by teaching staff who are likely uninformed of the latest in clinical guidelines with respect to caries and its clinical (non-surgical and surgical) management."

"It is difficult to change the way dentists treat patients. Often they think that caries progresses very quickly and that they need to restore any lesions seen on radiographs even when it is in enamel without giving a chance to arrest or remineralize."

"When students are in the clinic during the 3rd and 4th years, they are primarily supervised by part-time clinical instructors who dictate their own philosophies on caries management which do not prioritize medical caries management in spite of multiple efforts on calibration."

shown in Table 5. Finally, all participants expressed interest in organizing a workshop for developing or adopting a core cariology curriculum (European or U.S.) for Canadian dental schools.

\section{Discussion}

This study sought to assess the teaching of cariology in Canadian dental schools to provide a platform for further development of a curriculum framework for cariology education. Our results confirmed that cariology teaching in Canadian dental schools is evolving towards a contemporary caries management paradigm, especially in its didactic component. However, there are large challenges with implementing the theory in clinical practice. The participants' response rate was $100 \%$, which demonstrated a genuine interest in and recognition of the importance of the topic. All participants supported attending a future workshop designed to develop a core cariology curriculum for Canadian dental schools.

Our initiative is linked to similar work recently done in Europe, North and South America, and Asia. ${ }^{15,16,27,28}$ Predoctoral education in Canadian dental schools takes up to five years. Cariology didactic/ 
laboratory teaching is concentrated into the two first years of the curriculum in most institutions. In contrast, European predoctoral dental education requires up to six years: the theoretical cariology content is mostly presented in years two, three, and four, whereas pre-clinical cariology teaching appears in years two and three. ${ }^{15}$ Thus, it seems that theoretical cariology education is spread throughout the curriculum more in Europe than in Canada. Continuity of cariology teaching in all years could be beneficial for integration of a non-operative treatment philosophy into clinical practice.

In our study, cariology was taught by one department or by different divisions/departments and in a wide variety of courses in Canada. Similar findings, which may reflect the size and academic/administrative structure of dental schools, were found in reports from other countries. ${ }^{15,16,27,28}$ This similarity supports the need for a common approach in teaching cariology through different units. Five out of ten Canadian dental schools reported having a written cariology curriculum. However, we do not have information on their content, format, and implementation. In the U.S., $69 \%$ of dental schools reported having a defined cariology curriculum, ${ }^{16}$ while up to $75 \%$ of dental schools in Europe reported having a written curriculum. ${ }^{15}$ Harmonization of a cariology curriculum together with evidence-based teaching will help promote implementation of the contemporary cariology paradigm in dental schools. ${ }^{1}$

In Canadian dental schools, cariology is not seen as a separate discipline, as it is mostly viewed as a subtopic of other courses. This finding may suggest that cariology is not considered a separate field or that the dental education system has not adapted to teach the current caries paradigm. Another justification may relate to the evolution of Canadian dental schools' curricula, which have moved from discipline-based towards competency-based education, in which various courses address generic competencies. ${ }^{14,29}$ However, our results showed that there was no consensus among Canadian institutions on the content and format of the competencies related to cariology. Some schools used the ACFD framework, ${ }^{14}$ some used terminology from the NDEB, ${ }^{17}$ and others used specific learning outcomes. To ensure all dental students in Canada are optimally educated in cariology, a consensus among institutions on the core competencies, knowledge, skills, and abilities related to a cariology curriculum is needed in Canada.

Our survey found that all five curricular domains in the European and U.S. core cariology curricula were generally addressed by Canadian dental schools in didactic courses. ${ }^{11,13}$ Several topics were less frequently addressed: genetics and caries, Atraumatic Restorative Technique, management of salivary gland hypofunction, and assessment of readiness for behavioral change. These results are compatible with those from other surveys ${ }^{16,28}$ and may be used to define areas for improvement in cariology teaching.

Six universities used the same primary textbook for cariology education, ${ }^{18}$ which is in accord with the findings of a Colombian study. ${ }^{28}$ At the same time, a variety of other sources, including an operative dentistry textbook, ${ }^{19}$ were reported. This variation may reflect a diverging view on the knowledge base that is prioritized. A common, evidence-based source of information in cariology, adapted for the needs of clinicians, educators, and dental students, could improve the consistency of education across Canada and with the rest of the world.

Although several Canadian dental schools focused on the non-operative management of carious lesions in preclinical labs (e.g., carious lesion detection, caries risk assessment, and placement of dental sealants), some were still centered on operative techniques. Encouragingly, nine Canadian schools didactically addressed carious lesions activity assessment, and seven schools charted lesion activity in clinic. These findings can be considered an important step towards implementation of the contemporary caries paradigm. In contrast, in the Colombian survey, activity assessment was taught didactically by $65 \%$ of responding dental schools, ${ }^{28}$ while in the U.S. carious lesion activity was charted in clinic by $58 \%$ of responding dental schools. ${ }^{16}$ We found that six Canadian dental schools taught the ICDAS terminology and criteria, which is consistent with the results of the U.S. (65\%) and Colombian (61\%) surveys. ${ }^{16,28} \mathrm{In}$ clinical settings, we found a discordance in charting severity of carious lesions: eight Canadian dental schools charted non-cavitated lesions, four charted micro-cavitated lesions, six charted cavitated lesions, and four schools used the term "watch" for caries charting. This variation may represent a lack of integration of caries diagnosis concepts into clinical practice. Encouragingly, there was a consensus among all respondents on the radiographic threshold for operative treatment: lesions that reach the middle and inner third of dentin. However, the respondents noted that clinical teaching does not always follow didactic guidelines. Our findings agreed with previous studies showing heterogeneity in operative and non-operative treatment decisions in dental schools. ${ }^{16,27,28}$ 
According to our results, many caries risk assessment (CRA) tools were in use by Canadian dental schools, which could be explained by the absence of a validated CRA instrument for use in the Canadian population. ${ }^{30}$ Although CRA is didactically taught in all Canadian dental schools, there is an obvious issue with implementing the CRA strategy in clinical training across all years of education. The same challenge was reported in the Colombian survey. ${ }^{28}$

The limitations of this study related to the small sample size (although all ten Canadian dental schools participated), possible information bias on the survey, and lack of in-depth information that could be better gathered with a qualitative research approach. However, we used the same questionnaire used in the U.S. survey ${ }^{16}$ so our results are comparable. In spite of the limitations, our study provides a current overview of the current state of cariology education in dental schools in Canada.

Overall, all the Canadian dental schools reported significant challenges in transferring didactic cariology teaching into clinical dental education. Several issues are related to this: lack of uniformity in using caries classification systems; insufficient emphasis on non-surgical management of caries and prevention; lack of continuity in applying caries risk assessment during all clinical education; lack of consensus in the threshold for operative treatment decisions in clinic; and lack of education and training of clinical instructors for caries diagnosis and management. Our findings are consistent with reports from other studies emphasizing the challenges of implementing cariology education in clinical settings. ${ }^{9,16,28}$ The presence of all these challenges point to the importance and necessity of collaborative efforts among Canadian dental schools to understand the reasons for the existing problems and developing common solutions. We believe that a converged, co-constructed framework for cariology competence will be a strong strategic tool to foster needed changed in cariology teaching, accelerating adoption of evidence-based caries control approaches into clinical practice. In parallel, there is a need to evaluate the integration of the cariology management paradigm into clinical dental education through research. ${ }^{1}$

\section{Conclusion}

Contemporary cariology concepts are in the process of being implemented in didactic education across all Canadian dental schools. The greatest challenge met by all Canadian schools is an appropriate integration of cariology education into clinical practice. Continuous and obligatory theoretical and clinical training of clinical teachers for evidence-based dental caries diagnostic and management approaches and prioritizing a non-operative caries management approach in clinical settings may facilitate this process. In addition, there is a need for harmonization of evidence-based cariology teaching in Canadian dental schools to ensure that dental students are appropriately trained to implement the current caries paradigm in practice.

\section{REFERENCES}

1. Schwendicke F, Domejean S, Ricketts D, Peters M. Managing caries: the need to close the gap between the evidence base and current practice. Br Dent J 2015;219:433-8.

2. Fejerskov O, Escobar G, Jossing M, Baelum V. A functional natural dentition for all and for life? The oral health care system needs revision. J Oral Rehabil 2013;40:707-22.

3. Frencken JE, Innes NP, Schwendicke F. Managing carious lesions: why do we need consensus on terminology and clinical recommendations on carious tissue removal? Adv Dent Res 2016;28:46-8.

4. Elderton RJ. Preventive (evidence-based) approach to quality general dental care: medical principles and practice. Int J Kuwait Univ 2003;12(Suppl 1):12-21.

5. Ismail A, Brodeur JM, Gagnon P, et al. Restorative treatments received by children covered by a universal, publicly financed, dental insurance plan. J Public Health Dent 1997;57:11-8.

6. Innes NP, Schwendicke F. Restorative thresholds for carious lesions: systematic review and meta-analysis. J Dent Res 2017;96:501-8.

7. Rechmann P, Domejean S, Rechmann BM, et al. Approximal and occlusal carious lesions: restorative treatment decisions by California dentists. J Am Dent Assoc 2016; 147:328-38.

8. Baelum V. What is an appropriate caries diagnosis? Acta Odontol Scand 2010;68:65-79.

9. Fontana M, Zero D. Bridging the gap in caries management between research and practice through education: the Indiana University experience. J Dent Educ 2007;71 (5):579-91.

10. DePaola DP, Slavkin HC. Reforming dental health professions education: a white paper. J Dent Educ 2004;68 (11):1139-50.

11. Schulte AG, Pitts NB, Huysmans MC, et al. European core curriculum in cariology for undergraduate dental students. Eur J Dent Educ 2011;15(Suppl 1):9-17.

12. Pitts N, Melo P, Martignon S, et al. Caries risk assessment, diagnosis, and synthesis in the context of a European core curriculum in cariology. Eur J Dent Educ 2011;15(Suppl 1):23-31.

13. Fontana M, Guzman-Armstrong S, Schenkel AB, et al. Development of a core curriculum framework in cariology for U.S. dental schools. J Dent Educ 2016;80(5):705-20.

14. Association of Canadian Faculties of Dentistry. Educational framework for the development of competency in dental programs. 2016. At: acfd.ca/about-acfd/publications /acfd-competencies/. Accessed 30 June 2017. 
15. Schulte AG, Buchalla W, Huysmans MC, et al. A survey on education in cariology for undergraduate dental students in Europe. Eur J Dent Educ 2011;15(Suppl 1):3-8.

16. Fontana M, Sharples S, Wolff M, Young D. Teaching of cariology in U.S. dental schools. J Dent Res 2012;91:313.

17. National Dental Examining Board of Canada. At: ndebbned.ca/en. Accessed 30 June 2017.

18. Fejerskov O, Nyvad B, Kidd E. Dental caries: the disease and its clinical management. 3rd ed. Oxford, UK: Wiley Blackwell, 2015.

19. Robbins JW, Schwartz RS. Fundamentals of operative dentistry: a contemporary approach. New York: Quintessence, 2006.

20. Kidd E. Essentials of dental caries. 3rd ed. Oxford, UK: Oxford University Press, 2005.

21. Edgar WM, Dawes C. Saliva and oral health. London: British Dental Association, 2004.

22. García-Godoy HN, Nathe CN. Primary preventive dentistry. New York: Pearson Education, 2013.
23. Limeback H. Comprehensive preventive dentistry. New York: Wiley-Blackwell, 2012.

24. Murray JJ, Nunn JH, Steele JG. The prevention of oral disease. New York: Oxford University Press, 2003.

25. Deery C, Hosey MT, Waterhouse PJ. Paediatric cariology. New York: Quintessence, 2004.

26. Roberson TM, Swift JJ. Art and science of operative dentistry. 5th ed. St. Louis: C.V. Mosby, 2006.

27. Fukushima M, Iwaku M, Mjor IA. Cariology in Japanese dental schools. Int Dent J 2004;54:269-72.

28. Martignon S, Gomez J, Tellez M, et al. Current cariology education in dental schools in Spanish-speaking Latin American countries. J Dent Educ 2013;77(11):1330-7.

29. Chambers DW. Toward a competency-based curriculum. J Dent Educ 1993;57(11):790.

30. Tellez M, Gomez J, Pretty I, et al. Evidence on existing caries risk assessment systems: are they predictive of future caries? Community Dent Oral Epidemiol 2013; 41:67-78 